\title{
FACTORS RELATING TO DEPRESSIVE SYMPTOMS AMONG ELDERLY PEOPLE WITH CHRONIC VESTIBULAR DYSFUNCTION
}

\author{
Juliana Maria Gazzola , Mayra Cristina Aratani², Flávia Doná3, Camila Macedo 4 , \\ Márcia Maiumi Fukujima ${ }^{5}$, Maurício Malavasi Ganança ${ }^{6}$, Fernando Freitas Ganança ${ }^{7}$
}

\begin{abstract}
Objective: To identify factors relating to depressive symptoms among elderly people with chronic vestibular dysfunction. Method: This was a cross-sectional study in which 120 elderly people with chronic vestibular dysfunction answered the Geriatric Depression Scale questionnaire. Multivariate linear regression analysis was performed $(p<0.05$ and $95 \% \mathrm{Cl})$. Results: The patients presented a mean score of $12.86 \pm 6.39$ points on the Geriatric Depression Scale, and 67 of them (55.8\%) scored above the cutoff of 11 points. The predictive model for worsening of depressive symptoms was composed of female gender, memory and concentration disorders, insomnia, hearing disorders, poor sight, nonuse of walking aids and greater emotional impact of dizziness. Conclusion: Greater numbers of depressive symptoms among elderly people with chronic vestibular disease were related to the presence of memory and concentration disorders, insomnia, hearing disorders, very poor sight, greater emotional impact of dizziness, female gender and nonuse of walking aids.
\end{abstract}

KEY WORDS: risk factors, depression, elderly people, vestibular disease.

\section{Fatores relacionados aos sintomas depressivos de idosos com disfunção vestibular crônica}

Resumo - Objetivo: Identificar os fatores relacionados aos sintomas depressivos de idosos com disfunção vestibular crônica. Método: Estudo transversal, em que 120 idosos com disfunção vestibular crônica submeteram-se ao questionário Geriatric Depression Scale. Realizou-se análise de regressão linear multivariada ( $p<0,05$ e IC de 95\%). Resultados: Os pacientes apresentaram média de 12,86 $\pm 6,39$ pontos no GDS, sendo que 67 idosos $(55,8 \%)$ pontuaram acima da nota de corte 11 . O modelo preditivo para piora dos sintomas depressivos foi composto por gênero feminino, distúrbios de memória e da concentração, insônia, hipoacusia, visão péssima, não utilização de dispositivo de auxílio à marcha e maior impacto da tontura no aspecto emocional. Conclusão: O maior número de sintomas depressivos de idosos vestibulopatas crônicos está relacionado à presença de distúrbios de memória e da concentração, insônia, hipoacusia, visão péssima, maior impacto da tontura no aspecto emocional, gênero feminino e não utilização de dispositivo de auxílio à marcha.

PALAVRAS-CHAVE: fatores de risco, depressão, idoso, doença vestibular.

Vertigo and other forms of dizziness of vestibular origin are very common in senile populations. In addition to vertigo, other types of dizziness or instability, together with secondary autonomic symptoms like sweating, nausea and vomiting, may arise from dysfunctions of the vestibular system ${ }^{1}$. Many patients with dizziness deliberately restrict their physical activities, travel and social encounters. Through this, they aim to reduce the risk that these disagreeable symptoms might appear and to avoid the social embarrassment and stigma that they may cause.

Tinetti et al. ${ }^{2}$ conducted a study among a representative cohort of community-living elderly people in New

\footnotetext{
'Pt, MsC, Specialist in Gerontology, Federal University of São Paulo and Bandeirante University of São Paulo, São Paulo SP, Brazil; ${ }^{2} \mathrm{Pt}$, MsC, Specialist in Gerontology, Federal University of São Paulo, São Paulo SP, Brazil; ${ }^{3} \mathrm{Pt}$, PhD, Federal University of São Paulo and Bandeirante University of São Paulo, São Paulo SP, Brazil; ${ }^{4}$ Pt, Specialist in Gerontology, Federal University of São Paulo, São Paulo SP, Brazil; ${ }^{5} \mathrm{MD}$, PhD (Neurology) from Federal University of São Paulo, São Paulo SP, Brazil; ${ }^{6}$ MD, PhD, Professor of Otorhinolaryngology, Federal University of São Paulo, Bandeirante University of São Paulo, São Paulo SP, Brazil; ${ }^{7} \mathrm{MD}$, PhD, Professor of Otorhinolaryngology, Federal University of São Paulo, Bandeirante University of São Paulo, São Paulo SP, Brazil.
}

Received 4 December 2008, received in final form 3 February 2009. Accepted 24 April 2009.

Dra. Juliana Maria Gazzola - Disciplina de Otoneurologia da UNIFESP / EPM - Setor de Reabilitação Vestibular - Rua Pedro de Toledo 943 - $04039-032$ São Paulo SP - Brasil. E-mail: otoneuro@unifesp.epm.br 
Haven, Connecticut, USA (1087 participants) and observed that there was an association between chronic dizziness and worsening of depressive symptoms, self-assessed health conditions and participation in social activities. The psychosomatic consequences of dizziness caused by vestibular disorders may include anguish, anxiety and panic attacks, fear of going out alone, interference in daily activities, feelings of being outside of reality, depersonalization and depressed mood mof $^{3-6}$.

Mood disorders are one of the most common psychiatric abnormalities among elderly people and are responsible for loss of autonomy and worsening of preexisting pathological conditions ${ }^{7}$. Among these, depression is the most frequent clinical condition among elderly individuals. Epidemiological studies have indicated prevalence rates ranging from 1 to $16 \%$ among community-living elderly people $e^{8,9}$.

The Geriatric Depression Scale (GDS) is one of the instruments most frequently used for screening for depressive symptoms or for vulnerability towards depression among elderly populations. The GDS consists of 30 short questions with responses of yes/no type, covering the week preceding the assessment. It has the aim of rapidly screening for cases of depression among elderly patients, taking 15 minutes on average to apply it. Yesavage et al. ${ }^{10}$ suggested that a cutoff score of 11 should be used, for which they found sensitivity of $84 \%$ and specificity of $95 \%$ for detecting cases of depression among elderly individuals. The association between vestibular dysfunction and depression is fairly well known, but has been little investigated among elderly people, largely because of the lack of any truly integrated multidisciplinary approach for such patients. Identifying the prevalence of depressive symptoms or factors associated with depression among elderly people with chronic vestibular disease, by means of the GDS, is important for clinical practice, to make it possible to have a more precise diagnosis and the appropriate therapeutic management.

The aim of the present study was to determine the sociodemographic, otoneurological, clinical-functional, quality-of-life, psychocognitive and balance factors relating to depressive symptoms among elderly individuals with vestibular dysfunction.

\section{METHOD}

This was an analytical descriptive cross-sectional study with prior approval from the Research Ethics Committee of the Federal University of São Paulo - Escola Paulista de Medicina (UNIFESP-EPM), under protocol number 749/08. All the patients included in the study signed a free and informed consent statement.

The sample was made up of patients coming from the Otoneurology Outpatient Clinic of UNIFESP-EPM. All these pa- tients were 65 years of age or older, of either male or female gender, with chronic vestibular dysfunction characterized by complaints of dizziness and/or losing their balance, giddiness and/or other nonspecific feelings of dizziness, for at least three months.

The following elderly individuals were excluded from the study: those who presented physical, cognitive or sensory limitations that might hinder carrying out balance tests, such as an inability to understand or comply with simple verbal commands and/or to imitate movements; those who presented severely diminished visual and/or auditory acuity that absolutely incapacitated them with regard to their activities of daily living, even with the use of corrective lenses and/or sound amplification devices; those who had had amputations of upper or lower limbs; those who were unable to walk independently or whose locomotion was solely by means of a wheelchair; and those who had undergone any form of body balance rehabilitation within the six months preceding the assessment. The assessments were not performed while the patients were experiencing vertiginous crises.

The elderly individuals firstly underwent a clinical otoneurological evaluation, which included taking their histories and performing physical and otorhinolaryngological examinations, audiometry and immittance metering. Vestibular examinations were performed by means of vector-electronystagmography, in accordance with the criteria proposed by Ganança et al.".

Sociodemographic, otoneurological, clinical-functional, quality-of-life, psychocognitive and balance variables were analyzed. The sociodemographic data evaluated were gender, age (in completed years), marital status, schooling level attained and housing type. The clinical-functional data evaluated were the number of diseases present, number of medications taken, subjective perception of eyesight ${ }^{12}$, use of a walking aid and occurrences of falls. The otoneurological data evaluated included the syndromic and topographic diagnoses of the vestibular dysfunction (normal / deficient peripheral / irritative peripheral / central); number of associated vestibular complaints; time when dizziness starts; type, periodicity, duration and intensity of dizziness; and positions or activities in which episodes of dizziness occurred.

The positions or activities relating to the appearance of dizziness were investigated as described by Tinetti et al. ${ }^{3}$, namely: getting up from a lying-down position; turning the head; turning the body; getting up from a seated position; walking; when anxious; specific head positions; seated and motionless; changing position in bed; during exercise; and lying down on one side. The possible otoneurological and associated symptoms investigated were the presence or absence of tinnitus, auricular pressure/ fullness, hypersensitivity to sounds, hearing deficit, oscillopsia, headache, sweating/paleness/tachycardia, nausea, vomiting, insomnia, fear, feeling of imminent fainting and memory and concentration disorders.

To evaluate the impact of dizziness on quality of life, the Brazilian version of the Dizziness Handicap Inventory (DHI) was 
applied $^{13}$. For the cognitive assessment, the Mini-Mental State Examination (MMSE) was used ${ }^{14}$, and to detect depressive symptoms, the Geriatric Depression Scale (GDS) ${ }^{10}$. To assess balance, three previously validated functional instruments were used: Berg Balance Scale (BBS) ${ }^{15}$, Timed Up and Go Test (TUGT) ${ }^{16}$; and Dynamic Gait Index (DGI) ${ }^{17}$. Functional capacity was evaluated by means of the Brazilian OARS Multidimensional Functional Assessment Questionnaire (BOMFAQ) ${ }^{12}$, which evaluates the reported difficulty in performing 15 previously validated activities of daily living (ADLs), of which eight were physical activities and seven were instrumental activities.

The dependent variable analyzed was the total score from the GDS instrument ${ }^{10}$. The presence of associations between this variable and the other, independent variables was analyzed by means of the Mann-Whitney and Kruskal-Wallis tests and Spearman's correlation coefficient $(\rho)$. Variables presenting a significance level of less than 0.150 in univariate analysis were selected for multivariate analysis. To analyze the correlations between the different variables selected and the dependent variable, linear regression analysis was performed, using the stepwise criterion for selecting the variables. For the final model, only the variables with descriptive levels less than 0.050 were kept, as selected from the multivariate regression analysis.

\section{RESULTS}

The sample for this study comprised 120 elderly individuals with a medical diagnosis of chronic vestibular syndrome who were being followed up as outpatients. Among them, $68.3 \%$ were female and $31.7 \%$ were male, and the mean age was 73.40 years, with 5.77 standard deviation (SD). The mean number of diseases associated with the vestibular condition was $3.83 \pm 1.84$ and the mean number of medications taken was $3.86 \pm 2.27$. The vestibular examination showed that $29.8 \%$ of the patients presented vestibular disease with a unilateral peripheral deficit. The most prevalent diagnostic hypotheses were metabolic labyrinth disease (40.0\%) and benign paroxysmal positional vertigo (36.7\%). For 52 patients (43.3\%), their dizziness had started more than five years earlier. With regard to falls, 64 of the elderly individuals (53.3\%) had fallen at least once during the preceding year, and 35 (29.2\%) reported recurrent falls. The full sociodemographic, clinical-functional and otoneurological characterization of the sample was described in an earlier paper ${ }^{6}$.

In the cognitive assessment using the MMSE, most of the elderly vestibular disease patients (66.7\%) scored more than the cutoff of 23 points, thus identifying problems within this functional dimension. The mean score for the sample was 24.47 points (SD 3.30), with minimum and maximum scores of 14 and 30 , respectively.

In evaluating the mental state using the GDS, 67 elderly individuals (55.8\%) scored more than the 11 points cutoff, which suggests that they presented depressed mood.
The mean score for the sample was 12.86 points (SD 6.39), with a minimum score of zero and a maximum score of 28 points.

Higher scores in the GDS were associated with the variables that were found to present descriptive levels of less than $15 \%$ in the univariate analysis (Table 1). Such scores, i.e. greater numbers of depressive symptoms, were found among women and among elderly individuals without a partner, with greater number of diseases, without diseases of the circulatory system, with mental and behavioral disorders, with eye and adnexal diseases and with osteomuscular system and conjunctive tissue diseases; and

Table 1. Variables selected from univariate analysis on 120 elderly individuals with chronic vestibular dysfunction (limit of $p<0.15$ ).

\begin{tabular}{|c|c|}
\hline Variables & $\mathrm{p}$ \\
\hline Gender & 0.002 \\
\hline Marital status & 0.104 \\
\hline Number of diseases & 0.034 \\
\hline Diseases of the circulatory system & 0.094 \\
\hline Mental and behavioral disorders & 0.023 \\
\hline Eye and adnexal diseases & 0.111 \\
\hline Diseases of the osteomuscular system and conjunctive tissue & 0.006 \\
\hline Walking & 0.056 \\
\hline When anxious & 0.002 \\
\hline Falls during the preceding year & 0.030 \\
\hline Use of walking aid & 0.096 \\
\hline Subjective perception of eyesight & 0.034 \\
\hline Tinnitus & 0.116 \\
\hline Headache & 0.072 \\
\hline Memory and concentration disorders & $<0.001$ \\
\hline Hypersensitivity to sounds & 0.089 \\
\hline Nausea & 0.118 \\
\hline Vomiting & 0.052 \\
\hline Sweating / Paleness / Tachycardia & $<0.001$ \\
\hline Anxiety & 0.001 \\
\hline Feelings of fear & $<0.001$ \\
\hline Insomnia & $<0.001$ \\
\hline Oscillopsia & 0.039 \\
\hline Hearing deficit & 0.011 \\
\hline Dizziness Handicap Inventory (total score) & $<0.001$ \\
\hline Dizziness Handicap Inventory (physical score) & 0.013 \\
\hline Dizziness Handicap Inventory (emotional score) & $<0.001$ \\
\hline Dizziness Handicap Inventory (functional score) & $<0.001$ \\
\hline Functional capacity & $<0.001$ \\
\hline Dynamic Gait Index & 0.013 \\
\hline Berg Balance Scale & 0.093 \\
\hline
\end{tabular}


Table 2. Multiple linear regression analysis in relation to total score on the Geriatric Depression Scale and variables selected from univariate analysis.

\begin{tabular}{|c|c|c|c|}
\hline Variables & Estimated $\beta$ & Standard error & $\mathrm{p}$-value \\
\hline Intercept & 5.438 & 5.491 & 0.325 \\
\hline Gender & -1.017 & 1.241 & 0.415 \\
\hline Marital status & 0.691 & 1.062 & 0.517 \\
\hline Number of diseases & 0.156 & 0.301 & 0.604 \\
\hline Mental and behavioral disorders & 0.122 & 1.219 & 0.920 \\
\hline Eye and adnexal diseases & 1.273 & 0.993 & 0.203 \\
\hline Diseases of the circulatory system & -0.526 & 1.036 & 0.613 \\
\hline Diseases of the osteomuscular system and conjunctive tissue & 1.636 & 1.039 & 0.119 \\
\hline Walking & -1.603 & 0.935 & 0.090 \\
\hline When anxious & 0.962 & 0.861 & 0.267 \\
\hline Tinnitus & 0.112 & 0.938 & 0.904 \\
\hline Headache & 0.875 & 0.924 & 0.346 \\
\hline Memory and concentration disorders & 2.235 & 0.955 & 0.021 \\
\hline Hypersensitivity to sounds & -0.016 & 1.010 & 0.987 \\
\hline Nausea & -0.271 & 1.081 & 0.802 \\
\hline Vomiting & 1.142 & 1.296 & 0.380 \\
\hline Sweating/paleness/tachycardia & 0.749 & 0.949 & 0.432 \\
\hline Anxiety & 1.128 & 0.987 & 0.256 \\
\hline Feelings of fear & -0.024 & 0.953 & 0.980 \\
\hline Insomnia & 2.752 & 0.917 & 0.003 \\
\hline Oscillopsia & -0.447 & 0.937 & 0.635 \\
\hline Hearing deficit & 1.981 & 0.853 & 0.022 \\
\hline Subjective perception of eyesight & 2.041 & 0.839 & 0.017 \\
\hline Use of walking aid & -4.052 & 1.606 & 0.013 \\
\hline DHI (total score) & 0.541 & 0.467 & 0.250 \\
\hline DHI (physical subscale) & -0.663 & 0.469 & 0.160 \\
\hline DHI (emotional subscale) & -0.267 & 0.471 & 0.571 \\
\hline DHI (functional subscale) & -0.441 & 0.472 & 0.353 \\
\hline Functional capacity & 0.099 & 0.159 & 0.534 \\
\hline Dynamic Gait Indices & -0.040 & 0.186 & 0.827 \\
\hline Berg Balance Scale (total score) & -0.060 & 0.114 & 0.598 \\
\hline Falls during the preceding year & -0.469 & 0.852 & 0.583 \\
\hline
\end{tabular}

Total $R^{2}$ : Coefficient of determination (\% of variability explained by the model). Total $R^{2}: 71.66$; Estimated $\beta$ : Value of angular coefficient " $\beta$ " on the straight-line regression Y=a+bX. "a": intercept (first value); Dependent variable: Geriatric Depression Scale.

among those who reported dizziness when walking and when anxious, those who reported such otoneurological symptoms, those who said their sight was extremely poor sight, those who did not use walking aids, those for whom dizziness had a major impact on quality of life, those with functional impairment, those with worse performance in the functional gait and balance tests and those who reported they had suffered falls during the preceding year.

These variables presented significance levels of less than 0.150 in univariate analysis and were selected for multiple linear regression analysis in relation to the total score for the GDS (Table 2).

Table 3 presents the final model from the multiple linear regression analysis on the total score from the GDS, by means of the stepwise variable selection process. It was observed from this model that the variables of memory and concentration disorders, insomnia, hearing deficit, perception of eyesight and use of walking aids presented 
Table 3. Final model from multiple linear regression analysis in relation to the total score on the Geriatric Depression Scale among elderly individuals with chronic vestibular dysfunction ( $n=120)$.

\begin{tabular}{lccc}
\hline Variables & Estimated $\beta$ & Standard error & $\mathrm{p}$-value \\
\hline Intercept & 3.576 & 0.999 & 0.005 \\
Gender & -2.092 & 0.823 & 0.012 \\
Memory and concentration disorders & 1.786 & 0.858 & 0.039 \\
Insomnia & 3.544 & 0.784 & 0.001 \\
Hearing deficit & 2.581 & 0.759 & 0.001 \\
Subjective perception of eyesight & 1.503 & 0.733 & 0.042 \\
Use of walking aid & -2.991 & 1.257 & 0.019 \\
DHI (emotional subscale) & 0.366 & 0.040 & 0.001 \\
\hline
\end{tabular}

Total $R^{2}$ : Coefficient of determination (\% of variability explained by the model). Total $R^{2}: 64.11$; Estimated $\beta$ : Value of angular coefficient " $\beta$ " on the straight-line regression $Y=a+b X$. "a": intercept (first value); Dependent variable: Geriatric Depression Scale.

correlation with the GDS in multivariate analysis. In this model, the variables predicting higher scores on the GDS, i.e. greater numbers of depressive symptoms, were memory and concentration disorders, insomnia, hearing deficit, subjective perception of poor eyesight and greater scores on the emotional subscale of the DHI. On the other hand, the variables predicting lower scores on the GDS, i.e. smaller numbers of depressive symptoms, were male gender and use of walking aids. The final model explained $64.11 \%$ of the variability of the GDS $\left(R^{2}=0.6411\right)$.

\section{DISCUSSION}

Among elderly people with chronic vestibular disease, dizziness and poor balance may cause panic and anxiety, health worries and fear of performing activities that might trigger dizziness and consequently lead to falls, injuries or social embarrassment. On the other hand, psychological problems and the act of avoiding certain activities that might trigger or exacerbate dizziness considerably affect the quality of life of elderly people and members of their families ${ }^{4}$.

In evaluating the depressive symptoms, we observed that more than half of the sample presented scores suggestive of depressed mood. The prevalence of depressed mood that we found was greater than what was seen by Tusa $^{18}$, in which $40.0 \%$ of all of the patients with dizziness presented psychological dysfunctions.

The sample in the present study behaved very similarly to the community-living elderly population observed by Ramos et al. ${ }^{19}$, in relation to the cognitive assessment. However, because individuals with a medical diagnosis of dementia and those who were incapable of understanding simple verbal commands or imitating movements were eligible for inclusion in the present sample, some subjects with severe cognitive deficits may have been excluded, thereby diminishing the prevalence of elderly people with cognitive abnormalities.
Paradela et al..$^{20}$ observed in their validation study on the GDS that, among the 302 elderly people evaluated, the majority were female but without any association between gender and depressed mood. On the other hand, the predictive model observed in the present study showed that men were twice as likely to present depressed mood.

Psychological symptoms may be caused by the physical insecurity resulting from balance disorders ${ }^{21}$. There is a tendency towards a significant association between worse performance relating to functional balance and the symptom of anxiety ${ }^{22}$.

The total score for the BBS presented a tendency towards a significant but weak negative correlation with the GDS, in evaluating metal health, thus suggesting that the worse performance in functional balance among the patients with chronic vestibular disease was associated with depressed mood. This would be concordant with the findings of Tinetti et al. ${ }^{2}$, who observed an association between chronic dizziness and worsened depressive symptoms, with regard to self-assessed health conditions and participation in social activities.

Using any type of walking aid provides elderly people with greater security in moving their bodies and consequently better functional balance. This may be the reason in the present sample, for the protection that the use of walking aids provided for the elderly patients, i.e. for the elderly individuals with a number of depressive symptoms who were using them.

Sensory abnormalities have negative implications for elderly people's socioenvironmental interactions, and consequently may cause social isolation and dependence. In this light, the sensory deprivation experienced by elderly people may cause anxiety, thus worsening their depres$\operatorname{sion}^{23}$. Schneider et al. ${ }^{24}$ found an association between hearing deficit and lack of autonomy in a functional assessment on 148 elderly people. This reiterates the findings from 
the present study, in which it was seen that elderly people with dizziness and hearing deficit were twice as likely to present depressed mood. In a pilot study on 31 elderly people, Rovner et al. ${ }^{25}$ observed that depression was common and persistent among patients with poor sight. Leinhaas and Hedstrom ${ }^{26}$ reported that declining eyesight affected elderly individuals' social and emotional wellbeing and often preceded changes in social rules. These findings in the literature corroborate the present study, in which the elderly people with chronic vestibular function who reported a subjective perception that their sight was poor presented a greater chance of having a depressed mood.

Sá et al. ${ }^{27}$ showed that elderly people have a high prevalence of insomnia, ranging from 5 to $35 \%$. The older the study population is, the greater the tendency is towards increased prevalence of insomnia. The variable of insomnia remained in our final model as a predictor of depressive symptoms among elderly individuals with vestibular disease, probably because sleep deprivation interferes negatively with quality of life, thereby diminishing elderly people's capacity to concentrate, pay attention and remember things ${ }^{27}$. In 2003, in a study on insomniac elderly people, Morawetz ${ }^{28}$ concluded that the consequences of insomnia could be summarized as losses of concentration and memory, irritability, diminished ability to perform daily tasks, diminished pleasure in family and social relationships, and the possibility of triggering fatigue, asthenia, somnolence, loss of motivation and depressed mood.

There was much greater prevalence of memory and concentration disorders among the elderly patients with vestibular disease in the present study than in the study by Caovilla et al. ${ }^{29}$, which was on patients with vestibular disease in general and found that $12.6 \%$ were thus affected. Paiva and Kuhn ${ }^{30}$ found memory and concentration difficulties in $6.92 \%$ of their patients with vestibular disease, of whom $5.25 \%$ were female and $1.68 \%$ were male.

The emotional characteristics evaluated by the Brazilian DHI bring out the possibility that dizziness may harm patients' quality of life, thereby causing frustration, fear of going out alone or staying at home alone, embarrassment about the clinical manifestations, concern about self-image, concentration disorders, feelings of incapacity, changes in family or social relationships and depression $^{5}$. These consequences may explain why the emotional score of the DHI presents a tendency towards the condition of depressed mood among elderly individuals with vestibular disease.

In conclusion, greater numbers of depressive symptoms among elderly individuals with vestibular disease and chronic dizziness are associated with the presence of memory and concentration disorders, insomnia, hearing deficit, poor eyesight, greater emotional impact of dizziness, female gender and nonuse of walking aids.

\section{REFERENCES}

1. Ganança MM, Caovilla HH, Munhoz MSL, Silva MLG, Kuhn AMB, Ganança CF. Vertigem psicossomática. In Silva MLG, Munhoz MSL, Ganança MM, Caovilla HH. Quadros clínicos otoneurológicos mais comuns. Série Otoneurológica vol 3. São Paulo: Editora Atheneu 2000:145-151.

2. Tinetti ME, Williams CS, Gill TM. Health, functional and psychological outcomes among older persons with chronic dizziness. J Am Geriatr Soc 2000;48:417-421.

3. Tinetti ME, Williams CS, Gill TM. Dizziness among older adults: a possible geriatric syndrome. Ann Intern Med 2000;132:337-344.

4. Yardley L. Overview of psychologic effects of chronic dizziness and balance disorders. Otolaryngol Clin N Am 2000;33: 603-616.

5. Ganança FF, Castro ASO, Branco FCA, Natour J. Interferência da tontura na qualidade de vida de pacientes com síndrome vestibular periférica. Rev Bras Otorrinolaringol 2004; 70:94-101.

6. Gazzola JM, Ganança FF, Aratani MC, Perracini MR, Ganança MM. Caracterização clínica de idosos com disfunção vestibular crônica. Rev Bras Otorrinolaringol 2006;72:515-522.

7. Katona C, Livingston G, Manela M, et al. The symptomatology of depression in the elderly. Int Clin Psychopharmacol 1997;7: 19-23.

8. Kay DWK, Henderson AS, Scott R, et al. Dementia and depression among the elderly living in the Hobart community: the effect of the diagnostic criteria on the prevalence rates. Psychol Med 1985;5:771-788.

9. Veras RP, Murphy E. The mental health of older people in Rio de Janeiro. Int J Geriatr Psychiatry 1994;9:285-295.

10. Yesavage JA, Brink TL, Rose TL, et al. Development and validation of Geriatric Depression Screening Scale: a preliminary report. J Psychiatr Res 1983;17:37-49.

11. Ganança MM, Caovilla HH, Munhoz MSL, Silva MLG. Alterações da audição e do equilíbrio corporal no idoso. RBM Rev Bras Med 1999;56:995-1011.

12. Ramos LR, Rosa TEC, Oliveira ZMC, Medina MCG, Santos FRG. Perfil do idoso em área metropolitana na região sudeste do Brasil: resultados de inquérito domiciliar. Rev Saúde Públ 1993;27:87-94.

13. Castro ASO, Gazzola JM, Natour J, Ganança FF. Versão brasileira do Dizziness Handicap Inventory. Pró-Fono Revista de Atualização Científica 2007;19:97-104.

14. Bertolucci PHF, Brucki SMD, Capacci SR, Juliano Y. Mini-exame do estado mental em uma população geral: impacto da escolaridade. Arq Neuropsiquiatr 1994;52:1-7.

15. Miyamoto ST, Lombardi Junior I, Berg KO, Ramos LR, Natour J. Brazilian version of the Berg balance scale. Braz J Med Biol Res 2004;37:1-11.

16. Podsiadlo D, Richardson S. The timed "Up \& Go": a test of basic functional mobility for frail elderly persons. JAGS 1991; 39:142-148. 
17. Castro SM, Perracini MR, Ganança FF. Versão brasileira do Dynamic Gait Index. Rev Bras Otorrinolaringol 2006;72: 817-825.

18. Tusa RJ. Problemas psicológicos e o paciente com vertigem. In Herdman SJ. Reabilitação vestibular. Rio de Janeiro: Editora Manole 2002:312-315.

19. Ramos LR, Toniolo JN, Cendoroglo MS, et al. Two-year-up study of elderly residents in S. Paulo, Brazil: methodology and preliminary results. Rev Saúde Públi 1998;32:397-407.

20. Paradela EMP, Lourenço RA, Veras RP. Validação da escala de depressão geriátrica em ambulatório geral. Rev Saúde Públi 2005;39:918-923.

21. Caovilla HH, Ganança MM, Munhoz MSL, Silva MLG, Frazza MM. O valor da nistagmografia computadorizada. Rev Bras Otorrinolaringol 1997;4:158-163.

22. Gazzola JM. Fatores associados ao equilíbrio funcional em idosos com disfunção vestibular crônica. Dissertação. São Paulo: Universidade Federal de São Paulo, 2005.

23. Baptista MN, Morais PR, Rodrigues T, Silva JAC. Correlação entre sintomatologia depressiva e prática de atividades sociais em idosos. Avaliação Psicológica 2006;5:77-85.
24. Schneider RH, Marcolin D, Dalacorte RR. Avaliação funcional de idosos. Scientia Medica 2008;18:4-9.

25. Rovner BW, Zisselman PM, Shmuely-Dulitzki Y. Depression and disability in older people with impaired vision: a followup study. JAGS 1996;44:181-184.

26. Leinhaas MAM, Hedstrom NJ. Low vision: how to assess and treat its emotional impact. Geriatrics 1994;49:53-56.

27. Sá RMB, Motta LB, Oliveira FJ. Insomnia: prevalence and related risk factors in elderly outpatients. Rev Bras Geriatr Gerontol 2007;10:456-463.

28. Morawetz D. Insomnia and depression: wich comes first? Sleep 2003;5:77-88.

29. Caovilla HH, Ganança MM, Munhoz MSL, Silva MLG, Frazza MM. Dicas sobre vestibulopatias periféricas e centrais. Rev Bras Otorrinolaringol 1998;5:50-54.

30. Paiva DP, Kuhn AMB. Sintomas psicológicos concomitantes à queixa de vertigem em 846 prontuários de pacientes otoneurológicos do Ambulatório de Otoneurologia da Universidade de São Paulo- Escola Paulista de Medicina. Rev Bras Otorrinolaringol 2004;70:512-515. 